\title{
Maternal and cord blood adiponectin levels in relation to post-natal body size in infants in the first year of life: a prospective study
}

\author{
Zhe-qing Zhang, Qing-gui Lu, Jie Huang, Chang-ya Jiao, Shao-ming Huang and Li-mei Mao*
}

\begin{abstract}
Background: Adiponectin is an adipocyte hormone involved in energy homeostasis and metabolism. However, its role in early infancy is poorly understood.

Methods: We recruited a total of 443 pregnant women and their children in this prospective study. Cord blood samples were successfully obtained from 331 neonates. Maternal and umbilical blood serum adiponectin were measured. The weight-, height- and BMI-for-age Z scores of infants at birth and at 3, 6 and 12 months of age were assessed.

Results: Multiple linear regression analysis indicated that cord blood but not maternal serum adiponectin was positively associated with all of the anthropometric measures at birth $(P<0.01)$. Using Generalized Estimating Equation model after adjustment for sex, time, maternal age, gestational age, prepregnancy BMI, weight gain during pregnancy, maternal education, parity, history of miscarriage and mode of delivery, for every $1-\mu \mathrm{g} / \mathrm{ml}$ increment of maternal serum adiponectin, the height-for-age $Z$ score during the first year of life increased by $0.026(P=0.013)$ on average, and the height-for-age $Z$ score of infants in the highest quartile of maternal serum adiponectin was 0.270 (95\% Cl: $0.013-0.527)$ higher than those in the lowest quartile. The changes in weight-for-age $Z$ score from birth decreased by $0.67 \times 10^{-2}$ on average with every $1-\mu \mathrm{g} / \mathrm{ml}$ additional increase of cord blood adiponectin $(P=0.047)$. The infants in the highest quartile of cord blood adiponectin showed a -0.368 (95\% Cl, $-0.701--0.035)$ decrease in weight-for-age Z score change from birth compared with those in the lowest quartile.
\end{abstract}

Conclusions: Cord blood adiponectin concentration is a determinant of infant birth size and weight gain in the first year of life. Circulating maternal adiponectin during pregnancy may predict postnatal height growth.

Keywords: Adiponectin, Cord blood, Infant, Growth, Prospective study

\section{Background}

Obesity has received considerable attention as a major health threat with several etiologic influences [1]. Observational evidence suggests that a high birth weight and accelerated growth in infancy are associated with an increased risk of obesity in childhood and adulthood [2,3]. Accumulating evidence indicates that the development of obesity and its comorbidities may be influenced by intrauterine factors [4].

Adiponectin is an adipokine that is secreted by adipose tissue and correlates inversely with obesity in adults [5].

\footnotetext{
* Correspondence: mlm912@163.com

Department of Nutrition and Food Hygiene, Guangdong Provincial Key Laboratory of Tropical Disease Research, School of Public Health, Southern Medical University, Guangzhou 510515, People's Republic of China
}

It is also abundantly present in the cord blood of term neonates, at concentrations two to three times higher than those reported in adults [6]. However, studies to date have yielded markedly conflicting results on the relationship between maternal serum/cord blood adiponectin concentration and infant birth weight, ranging from an inverse association to no correlation to even a positive relationship [7-9]. Relatively few studies have evaluated the longer-term relationships of adiponectin level with growth $[8,10]$. Different ethnicities show varied levels of adiponectin [11], and the effect of pharmacologic agents that work by altering adiponectin levels also differs by ethnic group [12]. Studies in adults have established that ethnicity modifies the relationship between adiponectin and obesity, which may be partly due 
to differences in fat distribution particularly in the visceral compartment, the capacity for fat storage, genetic background and differential exposure to important environmental influences [12-14]. It is possible that ethnicity alters the relationship between adiponectin concentration and infant growth. Therefore, what applies to other ethnic populations might not apply to the Chinese population. However, up to now, no studies have been conducted to evaluate the effects of maternal and umbilical blood adiponectin levels on the postnatal growth of children in China. Additionally, most existing studies have estimated differences in adiponectin circulation associated with a change in anthropometric measures between two time points only, rather than with trajectories estimated from multiple measures of growth.

The primary aim of this study was to determine whether maternal and cord blood adiponectin levels are related to the growth of children in early infancy in China.

\section{Subjects and Methods Subjects}

The subjects were 443 pregnancy women aged 20-35 and their babies from a prospective cohort study in Guangzhou, China. They were recruited from the Maternal and Children's Hospital of BaiYun and Yuexiu District, Guangzhou between September 2010 and November 2011. All of the women had delivered normal single infants at full term. We excluded those with multiple births, a history of diabetes, chronic hypertension, endocrine disorders and /or other severe maternal illnesses. A detailed explanation of the study purposes, procedure and requirements was given to the subjects. Written informed consent was obtained from all the subjects before enrolment. The study protocol was approved by the research ethics board of Tongji Medical College, China.

\section{Data collection \\ Clinical and demographic data}

An interviewer-administered questionnaire was used to collect the demographic and historical information of the subjects, including their educational status, household income, personal medical and obstetrical history, information about their current pregnancy (including the delivery type, gestational duration, gender of the baby, the weight gain during pregnancy, and maternal pre-pregnancy weight) and height.

\section{Anthropometric measurements}

After delivery, maternal height was measured to the nearest $0.1 \mathrm{~cm}$ and weight to the nearest $0.5 \mathrm{~kg}$ while the subjects were wearing light clothing and no shoes. Measurements of the infants' weight $( \pm 0.1 \mathrm{~kg})$ and length $( \pm 0.1 \mathrm{~cm})$ were made at birth and at 3,6 , and 12 months of age $(+/-$ 15 days) according to standardised techniques by using an infant stadiometer (length board) and infant digital scale.
Body mass index (BMI) was calculated as weight (kilogram)/height in meters square.

\section{Adiponectin concentrations}

Venous blood samples of mothers were obtained in the morning after overnight fasting when they were admitted to the hospital awaiting delivery. A total of 331 cord blood samples were successfully collected from the umbilical vein after the delivery of the baby and before the delivery of the placenta. All of the blood samples were placed on ice packs, stored in styrofoam containers, and returned to our laboratory. On arrival, the blood samples were centrifuged and aliquoted, and frozen at $-80{ }^{\circ} \mathrm{C}$ until analysis. The adiponectin in the serum was determined by a commercially available ELISA (R\&D Systems, Wiesbaden, Germany). The intra- and interassay coefficients of variation were 5.4 and $7.0 \%$, respectively.

\section{Statistical analysis}

All analyses were conducted using SPSS 21.0 for Windows (SPSS, Inc., Chicago, USA). $P<0.05$ was considered significant. All continuous variables were expressed as mean \pm standard deviation, or median with inter-quartile range. They were checked for normality using the KolmogorovSmirnoff test. Categorical variables are presented as percentages.

The age- and sex-specific weight-, height- and BMI-for age Z-scores were generated based on the WHO standards [15]. Two multiple linear regression models using the enter method were applied to examine whether the correlations between the adiponectin level and body size measurements at birth were independent after adjustment for other potential covariates. In model 1, we adjusted for sex. And in model 2, we further adjusted for maternal age, gestational age, prepregnancy BMI, weight gain during pregnancy, maternal education, parity, history of miscarriage and mode of delivery. We did not log transform adiponectin since its residual plot did not indicate any violations of the linear regression model assumptions. The Generalized Estimating Equation (GEE) method with unstructured correlation matrix was used to estimate the relationship between the maternal and cord blood adiponectin levels and the weight-, heightand BMI-for age Z-scores at 3, 6 and 12 months of age, and their average changes from birth. This technique is applied to the analysis of longitudinal data that are an extension of generalised linear models, and was specially developed to account for autocorrelation due to serial measurements [16]. Analyses of the relationship between maternal/cord blood adiponectin concentration and anthropometric indicators and their changes at 3, 6 and 12 months of age were serially adjusted for confounding factors in two generalized estimating equation models: that is, a model adjusted for sex and time only; and a model 
adjusted for maternal age, gestational age, prepregnancy BMI, weight gain during pregnancy, maternal education, parity, history of miscarriage and mode of delivery in addition to sex and time. The adiponectin level was entered as either a continuous or a four-level categorical variable.

\section{Results}

\section{Selected characteristics of the study subjects}

Table 1 summarizes the characteristics of the study population and neonatal outcomes. The mean age of the study participants was 27.3 years and the median prepregnancy BMI was $19.8 \mathrm{~kg} / \mathrm{m}^{2}$. The median increase in weight at the end of pregnancy was $15.0 \mathrm{~kg}$. Fifty-two percent of the neonates were male. The median neonatal gestational age was 39.0 weeks. The adiponectin levels were significantly higher in the cord blood than in maternal serum $(39.6 \mu \mathrm{g} / \mathrm{ml}$ vs. $6.9 \mu \mathrm{g} / \mathrm{ml}, P<0.05)$. After adjustment for gestational age, weight gain during pregnancy and age, a weak positive correlation $(r=0.172, P=0.004)$ was observed in adiponectin levels in maternal vs. fetal circulation. The anthropometric parameters at each visit are

Table 1 Characteristics of the subjects

\begin{tabular}{|c|c|}
\hline Variables & Mean \pm SD/Median $(\mathrm{IQR})$ \\
\hline \multicolumn{2}{|l|}{ Maternal variables } \\
\hline Age at enrolment (year) & $27.3 \pm 4.2$ \\
\hline Pregnancy BMI (kg/m²) & $19.8(2.9)$ \\
\hline Weight gain during pregnancy (kg) & $15.0(6.0)$ \\
\hline Caesarean section (\%) & 47.9 \\
\hline \multicolumn{2}{|l|}{ Education (\%) } \\
\hline Junior high school or less & 41.2 \\
\hline Senior middle school & 32.4 \\
\hline High school or above & 26.6 \\
\hline \multicolumn{2}{|l|}{ Parity (\%) } \\
\hline 1 & 61.7 \\
\hline 2 & 28.4 \\
\hline 3 & 9.9 \\
\hline \multicolumn{2}{|l|}{ History of miscarriage (\%) } \\
\hline 0 & 84.4 \\
\hline 1 & 11.1 \\
\hline$\geq 2$ & 4.5 \\
\hline Maternal serum adiponectin $(\mu \mathrm{g} / \mathrm{ml})$ & $6.9(5.3)$ \\
\hline \multicolumn{2}{|l|}{ Newborn/infant variables } \\
\hline Male (\%) & 52.2 \\
\hline Length of gestation (weeks) & $39(2)$ \\
\hline Birth weight (g) & $3250(480)$ \\
\hline Birth length $(\mathrm{cm})$ & $50.0(1.0)$ \\
\hline Birth BMI $\left(\mathrm{kg} / \mathrm{m}^{2}\right)$ & $13.1 \pm 1.2$ \\
\hline Cord adiponectin $(\mu \mathrm{g} / \mathrm{ml})$ & $39.6(20.1)$ \\
\hline
\end{tabular}

BMI: body mass index; $S D$ : standard deviation; IQR: inter-quartile range showed in Additional file 1: Table S1. In general, the weight-, height- and BMI-for-age Z scores at birth were lower than the reference but higher at 3, 6 and 12 months (Additional file 1: Figure S1).

\section{Adiponectin level and neonatal weight-, height- and BMI-for-age Z score}

There were significant inverse associations between cord blood serum adiponectin level and the neonatal weight-, height- and BMI-for age Z scores (Table 2). After controlling for sex, maternal age, gestation age, prepregnancy BMI, weight gain during pregnancy, maternal education, parity, history of miscarriage and mode of delivery, for every $1-\mu \mathrm{g} / \mathrm{ml}$ increase in cord blood adiponectin, the weight-for-age $\mathrm{Z}$ score at birth increased by $1.00 \times 10^{-2}$ $(P<0.0001)$. Equivalent estimations of height- and BMIfor-age $\mathrm{Z}$ score at birth were $0.69 \times 10^{-2}(P=0.010)$ and $1.02 \times 10^{-2}(P=0.002)$, respectively. No significant relationships were detected between maternal serum adiponectin circulation and fetal anthropometrics.

\section{Adiponectin level and anthropometric measures and their changes after birth}

The GEE analysis of the associations between maternal and cord blood adiponectin and the weight-, heightand BMI-for age $\mathrm{Z}$ scores and their changes at 3, 6 and 12 months are shown in Table 3. After controlling for sex, time, maternal age, gestation age, prepregnancy BMI, weight gain during pregnancy, maternal education, parity, history of miscarriage and mode of delivery, for every $1-\mu \mathrm{g} / \mathrm{ml}$ additional increase of maternal blood adiponectin, the height-for-age $\mathrm{Z}$ score increased by $2.59 \times 10^{-2}$ on average during the follow-up period $(P=0.013)$. And the changes in weight-for-age $\mathrm{Z}$ score decreased by $0.67 \times$ $10^{-2}$ with every $1-\mu \mathrm{g} / \mathrm{ml}$ increment of cord blood adiponectin $(P=0.047)$.

When the maternal blood serum adiponectin levels were ranked in quartiles, the height-for-age $\mathrm{Z}$ score of infants in the highest quartile of maternal serum adiponectin was 0.270 (95\% CI: 0.013-0.527) higher than that in the lowest quartile (Fig. 1) after adjustment for covariates as mentioned above. Figure 2 demonstrates the associations between the quartiles for cord blood serum adiponectin and changes in the anthropometrics $\mathrm{Z}$ score. Infants in the highest quartile of cord blood adiponectin showed a -0.368 (95 \% CI, $-0.701--0.035)$ decrease in weight-forage $\mathrm{Z}$ score change and a $-0.395(-0.784-0.006)$ decrease in BMI-for-age $\mathrm{Z}$ score compared with the lowest quartile. No differences were found in the changes in body size $Z$ scores from birth among the quartiles for maternal serum adiponectin or in the body size $\mathrm{Z}$ scores themselves among the quartiles of cord blood adiponectin (data not shown). 
Table 2 Multiple linear regression analysis of the associations between maternal and cord blood adiponectin levels and weight-, height-, and BMl-for-age $\mathrm{z}$ scores at birth

\begin{tabular}{|c|c|c|c|c|c|c|}
\hline & \multicolumn{3}{|c|}{ Maternal blood APN } & \multicolumn{3}{|c|}{ Cord blood APN } \\
\hline & $\beta\left(\times 10^{-2}\right)$ & SE $\left(\times 10^{-2}\right)$ & $P$ & $\overline{\beta\left(\times 10^{-2}\right)}$ & SE $\left(\times 10^{-2}\right)$ & $P$ \\
\hline \multicolumn{7}{|c|}{ Weight-for-age Z score } \\
\hline Model 1 & -1.27 & 0.91 & 0.162 & 1.33 & 0.28 & $<0.0001$ \\
\hline Model 2 & -0.41 & 0.79 & 0.610 & 1.00 & 0.25 & $<0.0001$ \\
\hline \multicolumn{7}{|c|}{ Height- for-age Z score } \\
\hline Model 1 & -0.27 & 0.87 & 0.755 & 1.00 & 0.27 & $<0.001$ \\
\hline Model 2 & 0.44 & 0.84 & 0.598 & 0.69 & 0.27 & 0.010 \\
\hline \multicolumn{7}{|c|}{ BMl-for-age Z score } \\
\hline Model 1 & -1.72 & 1.10 & 0.117 & 1.25 & 0.33 & $<0.001$ \\
\hline Model 2 & -0.81 & 1.00 & 0.419 & 1.02 & 0.32 & 0.002 \\
\hline
\end{tabular}

Model 1: Adjusted by sex

Model 2: Adjusted by sex, maternal age, gestation age, prepregnancy BMI, weight gain in pregnancy preceding, maternal education, parity, history of miscarriage and mode of delivery, Method: entered

\section{Discussion}

This prospective study is the first to report the influence of maternal and cord blood adiponectin levels on neonatal weight-, height- and BMI-for-age Z score at birth and their changes at 3, 6 and 12 months of age. The main finding of our study is that cord blood adiponectin was positively associated with anthropometric measures at birth but inversely correlated with weight-for-age $\mathrm{Z}$ score changes from baseline during the first year of life after adjustment for potential covariates. Maternal blood adiponectin concentrations were significantly lower than those of the umbilical blood and showed a positive relationship with height-for-age $\mathrm{Z}$ score during the first year of life.

Table 3 GEE analysis of the associations between maternal and cord blood adiponectin levels and the anthropometric parameters and their changes from birth during the first year of life

\begin{tabular}{|c|c|c|c|c|c|c|}
\hline & \multicolumn{3}{|c|}{ Maternal blood APN } & \multicolumn{3}{|c|}{ Cord blood APN } \\
\hline & $\overline{\beta\left(\times 10^{-2}\right)}$ & SE $\left(\times 10^{-2}\right)$ & $P$ & $\beta\left(\times 10^{-2}\right)$ & SE $\left(\times 10^{-2}\right)$ & $P$ \\
\hline \multicolumn{7}{|c|}{ Weight-for-age Z score } \\
\hline Model 1 & 1.35 & 0.83 & 0.107 & 0.63 & 0.29 & 0.030 \\
\hline Model 2 & 1.63 & 0.81 & 0.044 & 0.36 & 0.28 & 0.199 \\
\hline \multicolumn{7}{|c|}{ Height-for-age Z score } \\
\hline Model 1 & 2.48 & 1.04 & 0.017 & 0.52 & 0.32 & 0.105 \\
\hline Model 2 & 2.59 & 1.05 & 0.013 & 0.19 & 0.32 & 0.560 \\
\hline \multicolumn{7}{|c|}{ BMI-for-age Z score } \\
\hline Model 1 & -0.27 & 0.72 & 0.709 & 0.59 & 0.28 & 0.034 \\
\hline Model 2 & 0.33 & 0.70 & 0.641 & 0.44 & 0.27 & 0.110 \\
\hline \multicolumn{7}{|c|}{ Changes in weight-for-age $Z$ score } \\
\hline Model 1 & 2.62 & 1.02 & 0.010 & -0.68 & 0.35 & 0.048 \\
\hline Model 2 & 1.92 & 0.99 & 0.051 & -0.67 & 0.34 & 0.047 \\
\hline \multicolumn{7}{|c|}{ Changes in height-for-age $Z$ score } \\
\hline Model 1 & 2.77 & 1.28 & 0.030 & -0.55 & 0.34 & 0.099 \\
\hline Model 2 & 2.09 & 1.29 & 0.105 & -0.50 & 0.33 & 0.120 \\
\hline \multicolumn{7}{|c|}{ Changes in BMI-for-age Z score } \\
\hline Model 1 & 1.78 & 1.07 & 0.090 & -0.65 & 0.41 & 0.112 \\
\hline Model 2 & 1.19 & 1.02 & 0.244 & -0.62 & 0.41 & 0.128 \\
\hline
\end{tabular}

Model 1: Adjusted by sex and time

Model 2: Adjusted by sex, time, maternal age, gestation age, prepregnancy BMI, weight gain in pregnancy, maternal education, parity, history of miscarriage and mode of delivery 


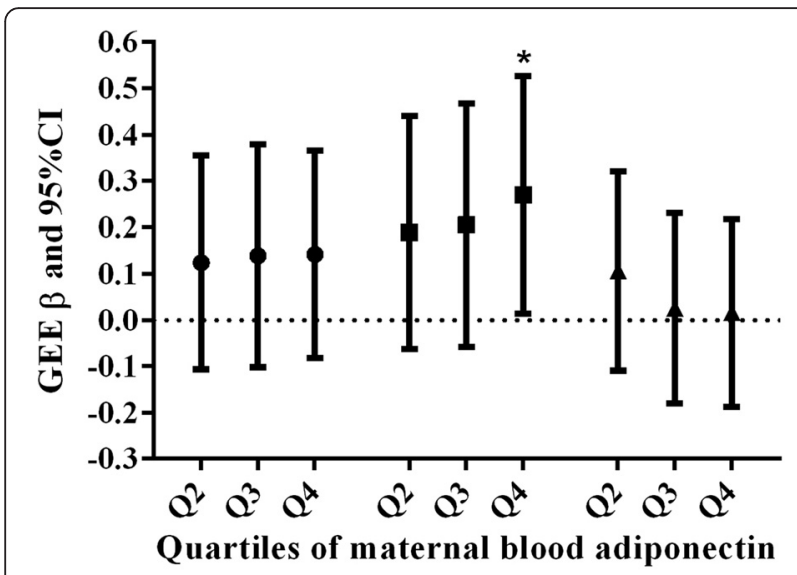

Fig. 1 GEE analysis of the relationship between quartiles of maternal serum adiponectin and body-size $Z$ score during the first year of life after adjustment for sex, time, maternal age, gestation age, prepregnancy $\mathrm{BMI}$, weight gain during pregnancy, maternal education, parity, history of miscarriage and mode of delivery. Weight-for-age Z score: $\bullet$; Height-forage Z score: $\mathbf{m}$; BMI-for-age Z score: $\boldsymbol{\Lambda}_{\text {; }}^{*}: P<0.05$. $\beta$ values represent difference in body size $Z$ score with the reference category, i.e., lowest quartile of adiponectin

We confirm data from previous observational studies showing that cord blood adiponectin levels were several folds higher than those seen in adults $[17,18]$. The recent study of Luo et al. observed a statistically significant positive correlation in adiponectin levels in maternal and fetal circulation $(r=0.3, P<0.0001)$ [19]. A significant positive correlation in adiponectin levels in maternal vs. fetal circulation adjusted by covariates was also detected in our data $(r=0.172, P=0.004)$. Genetic variation in the adiponectin

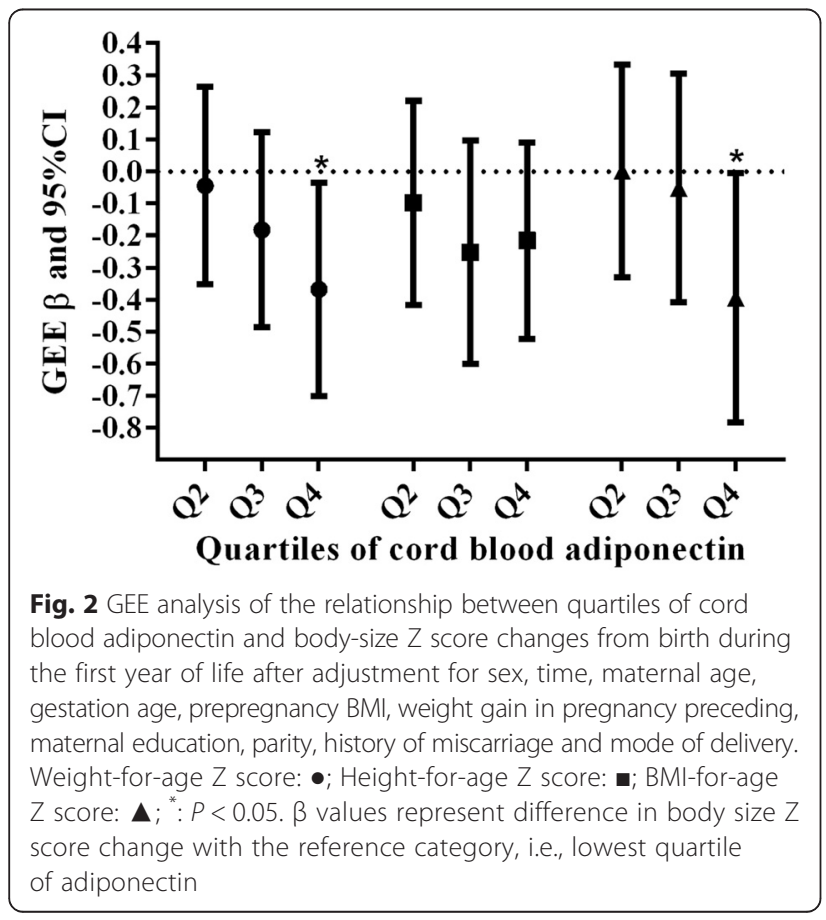

gene or its regulating elements may be responsible for this maternal-fetal correlation. In contrast, only nonstatistically significant positive correlations have been reported in most previous studies [6, 20,21]. Insufficient study power in some studies $(n=51-74)[20,21]$ and differences in the adjustment for potential confounders may partly explain the null findings in previous studies.

The positive correlation between cord blood adiponectin and fetal anthropometrics in our study is in agreement with some studies $[6,8,21]$ but not all $[22,23]$. Several factors may explain the lack of consistency in this regard. In the study of Lindsay et al., the absence of a significant association may be explained by the confounding effect of the existence of pre-disease states in some of the individuals included in the populations that were studied [9]. The other studies were limited by a small sample size (44-74), and thus they may have missed associations due to a lack of statistical power [20,22, 23]. Additionally, studies in adults have indicated that the correlations between adiponectin and adiposity are modulated by ethnicities [12] Whether ancestral background also accounts for disparities in the relationship between adiponectin and obesity in neonates needs to be further elucidated.

A few prospective studies have been conducted on the role of cord and maternal blood adiponectin levels in the postnatal growth of infants. In a sample of 588 children participating in the prospective prebirth cohort study Project Viva, Mantzoros et al. reported that cord blood adiponectin was inversely correlated with change in weight-for-length $\mathrm{Z}$ score $(r=-0.12 ; P=0.05)$ and weightfor-age $\mathrm{Z}$ score $(r=-0.10 ; P=0.04)$ from birth to 6 months but was not associated with change in length-for-age $\mathrm{Z}$ score $(r=0.03 ; P=0.61)[10]$. In agreement with the findings of Mantzoros et al. [10], we also found that neonates with a higher cord blood adiponectin gained less weight during the first year of life.

Most previous epidemiologic studies investigating the links between adiponectin levels and obesity in adults and children have demonstrated a negative relationship [24]. In fetal tissue, adiponectin is secreted not only by adipocytes, but also muscle and vascular cells, whereas in adult humans it is exclusively secreted by adipose tissue [25]. Fetal adipose tissue is also composed mainly of small newly differentiated adipocytes that lack the factors that are responsible for the inhibition of adiponectin production. Several lines of evidence suggest that senescent cells could accumulate in fat tissue with chronological aging and that these cells might contribute to age-related fat tissue inflammation and dysfunction [26]. Additionally, the available data suggest that brown adipose tissue (BAT) is more prevalent in children than in adults [27]. It is under strikingly different hormonal regulation than in white adipose tissue [28]. Moreover, adiponectin secretion from omental but not from sc adipocytes 
was negatively associated with measures of adiposity $[29,30]$. The different origination of adiponectin, a decreasing sc adipose tissue/visceral adipose tissue ratio, the atrophy of brown adipose tissue and metabolic function changes in adipocytes with increasing age may in part explain the switch from a positive correlation between adiponectin and weight at birth to a negative correlation later in life $[21,28,31]$. In the Nurses' Health Study, elevated adiponectin levels at baseline were associated with greater weight gain in healthy women [32], which is contrary to our findings in infants. The authors of the Nurses' Health Study hypothesized that elevated adiponectin levels in humans was a sign of healthy adipose tissue and its capacity to adapt to more fat accumulation [32]. However, cellular stress and adipocyte overutilization with ageing led to metabolic dysfunction [26]. The variation in the metabolic function of adipocytes such as fat storage, the secretion and response to the modulation of adiponectin may collectively contribute to the discrepancies between infants and adults. In addition, BAT is especially abundant during infancy and its activation protects against weight gain [33]. Additional studies are required to determine whether BAT modulates weight changes by altering the secretion of adiponectin. Furthermore, some evidence suggested that adiponectin could reduce food intake and increase energy expenditure through action on the hypothalamus, which also provided a potential explanation for the negative association between cord adiponectin and weight gain [34].

The association between maternal adiponectin concentration and fetal growth are less clear. A negative correlation with birth weight has been reported by some studies [7], but not others [35, 36]. In this study, maternal adiponectin level was not a determinant of fetal size at birth, but was positively correlated with the height-for-age $\mathrm{Z}$ score during the first year after adjustment for cofounders. In theory, maternal adiponectin is unable to pass through the placental barrier due to its large molecular weight. However, Aye et al. [37] and Rosario et al. [38] have reported that adiponectin infusion in pregnant mice downregulates placental amino acid transporter activity and expression and decreases fetal growth. Thus, it is possible that maternal adiponectin circulation potentially modulates placental function, which, in turn, may affect the intrauterine environment of the foetus and the postnatal growth of infants. Further human studies are warranted to verify this hypothesis.

The strength of our study is its prospective design and repeated measures of anthropometric parameters in infants. We are the first to report the associations between adiponectin concentrations in maternal and umbilical blood and infant growth in early infancy in a Chinese population. However, our study has some limitations. First, not all of the subjects consented to the assessment of umbilical adiponectin status; thus, the results may be subject to potential bias. Second, the results may not be easy to generalize to other ethnic groups. Third, similar to all other previous studies, we did not determine fat mass directly, and did not measure the centrality of fat distribution. Thus, it remains unknown whether there is a relationship between adiponectin and visceral fat in infants. Finally, anthropometric measures during the follow-up had about 5.3-6.0 \% missing data in our study. However, analyses after multiple imputation of the missing values yielded similar findings and thus our findings were not biased by the missing data.

\section{Conclusions}

Cord blood adiponectin is a determinant of fetal size at birth and weight gain during the first year of life. Maternal serum adiponectin during pregnancy may predict postnatal height growth.

\section{Additional file}

Additional file 1: Table S1. The anthropometric measures at 3,6 and 12 months of the infants. Figure S1. The Mean (SD) of weight-, height-, and BMl-for-age $z$ scores at 0, 3, 6, 12 months of age. (DOC $190 \mathrm{~kb}$ )

\section{Abbreviations}

BMI, body mass index; GEE, Generalized Estimating Equation; WHO, World Health Organization

\section{Acknowledgments}

This study was jointly supported by the National Natural Science Foundation of China (No. 81273072), the National Key Technology R\&D Program of China (No.2008BAI58B07), and a grant from the Medical Scientific Research Foundation of Guangdong Province, China (No. A2015020). We thank all of the subjects for their support.

\section{Authors' contributions}

MLM conceived of the idea and designed the study. ZZQ analysed the data and drafted the manuscript. LQG, HJ, JCY and HSM performed the study. All of the authors contributed to the interpretation of the results and approved the final manuscript.

\section{Competing interests}

The authors declare that they have no competing interests.

Received: 22 April 2015 Accepted: 18 July 2016

Published online: 27 July 2016

\section{References}

1. Nguyen DM, El-Serag HB. The epidemiology of obesity. Gastroenterol Clin North Am. 2010;39(1):1-7.

2. Baird J, Fisher D, Lucas P, Kleijnen J, Roberts H, Law C. Being big or growing fast: systematic review of size and growth in infancy and later obesity. BMJ. 2005;331(7522):929.

3. Yu ZB, Han SP, Zhu GZ, Zhu C, Wang XJ, Cao XG, et al. Birth weight and subsequent risk of obesity: a systematic review and meta-analysis. Obes Rev. 2011;12(7):525-42

4. Dunger DB, Ong KK. Endocrine and metabolic consequences of intrauterine growth retardation. Endocrinol Metab Clin North Am. 2005;34(3):597-615. ix.

5. Arita Y, Kihara S, Ouchi N, Takahashi M, Maeda K, Miyagawa J, et al. Paradoxical decrease of an adipose-specific protein, adiponectin, in obesity. Biochem Biophys Res Commun. 1999;257(1):79-83. 
6. Weyermann M, Beermann C, Brenner H, Rothenbacher D. Adiponectin and leptin in maternal serum, cord blood, and breast milk. Clin Chem. 2006; 52(11):2095-102.

7. Ong GK, Hamilton JK, Sermer M, Connelly PW, Maguire G, Zinman B, et al. Maternal serum adiponectin and infant birthweight: the role of adiponectin isoform distribution. Clin Endocrinol (Oxf). 2007:67(1):108-14.

8. Inami I, Okada T, Fujita H, Makimoto M, Hosono S, Minato M, et al. Impact of serum adiponectin concentration on birth size and early postnatal growth. Pediatr Res. 2007;61(5):604-6.

9. Lindsay RS, Walker JD, Havel PJ, Hamilton BA, Calder AA, Johnstone FD, et al. Adiponectin is present in cord blood but is unrelated to birth weight. Diabetes Care. 2003;26(8):2244-9.

10. Mantzoros CS, Rifas-Shiman SL, Williams CJ, Fargnoli JL, Kelesidis T, Gillman MW. Cord blood leptin and adiponectin as predictors of adiposity in children at 3 years of age: a prospective cohort study. Pediatrics. 2009;123(2):682-9.

11. Hulver MW, Saleh O, MacDonald KG, Pories WJ, Barakat HA. Ethnic differences in adiponectin levels. Metabolism. 2004:53(1):1-3.

12. Mente A, Razak F, Blankenberg S, Vuksan V, Davis AD, Miller R, et al. Ethnic variation in adiponectin and leptin levels and their association with adiposity and insulin resistance. Diabetes Care. 2010;33(7):1629-34.

13. Khoo CM, Sairazi S, Taslim S, Gardner D, Wu Y, Lee J, et al. Ethnicity modifies the relationships of insulin resistance, inflammation, and adiponectin with obesity in a multiethnic Asian population. Diabetes Care. 2011;34(5):1120-6.

14. Hanley AJ, Bowden D, Wagenknecht LE, Balasubramanyam A, Langfeld C, Saad MF, et al. Associations of adiponectin with body fat distribution and insulin sensitivity in nondiabetic Hispanics and African-Americans. J Clin Endocrinol Metab. 2007;92(7):2665-71.

15. Lang IA, Galloway TS, Scarlett A, Henley WE, Depledge M, Wallace RB, et al. Association of urinary bisphenol A concentration with medical disorders and laboratory abnormalities in adults. JAMA. 2008;300(11): 1303-10.

16. Yang Q, Graham TE, Mody N, Preitner F, Peroni OD, Zabolotny JM, et al. Serum retinol binding protein 4 contributes to insulin resistance in obesity and type 2 diabetes. Nature. 2005;436(7049):356-62.

17. Kotani Y, Yokota I, Kitamura S, Matsuda J, Naito E, Kuroda Y. Plasma adiponectin levels in newborns are higher than those in adults and positively correlated with birth weight. Clin Endocrinol (Oxf). 2004;61(4):418-23.

18. Pardo IM, Geloneze B, Tambascia MA, Barros-Filho AA. Hyperadiponectinemia in newborns: relationship with leptin levels and birth weight. Obes Res. 2004;12(3):521-4.

19. Luo ZC, Nuyt AM, Delvin E, Fraser WD, Julien P, Audibert F, et al. Maternal and fetal leptin, adiponectin levels and associations with fetal insulin sensitivity. Obesity (Silver Spring). 2013;21(1):210-6.

20. Bansal N, Charlton-Menys V, Pemberton P, McElduff P, Oldroyd J, Vyas A, et al. Adiponectin in umbilical cord blood is inversely related to low-density lipoprotein cholesterol but not ethnicity. J Clin Endocrinol Metab. 2006; 91(6):2244-9.

21. Sivan E, Mazaki-Tovi S, Pariente C, Efraty Y, Schiff E, Hemi R, et al. Adiponectin in human cord blood: relation to fetal birth weight and gender. J Clin Endocrinol Metab. 2003;88(12):5656-60.

22. Corbetta S, Bulfamante G, Cortelazzi D, Barresi V, Cetin I, Mantovani G, et al. Adiponectin expression in human fetal tissues during mid- and late gestation. J Clin Endocrinol Metab. 2005;90(4):2397-402.

23. Bozzola E, Meazza C, Arvigo M, Travaglino P, Pagani S, Stronati M, et al. Role of adiponectin and leptin on body development in infants during the first year of life. Ital J Pediatr. 2010;36:26.

24. Onat A, Hergenc G, Dursunoglu D, Kucukdurmaz Z, Bulur S, Can G. Relatively high levels of serum adiponectin in obese women, a potentia indicator of anti-inflammatory dysfunction: relation to sex hormone-binding globulin. Int J Biol Sci. 2008;4(4):208-14.

25. Pinar H, Basu S, Hotmire K, Laffineuse L, Presley L, Carpenter M, et al. High molecular mass multimer complexes and vascular expression contribute to high adiponectin in the fetus. J Clin Endocrinol Metab. 2008;93(7):2885-90.

26. Tchkonia T, Morbeck DE, Von Zglinicki T, Van Deursen J, Lustgarten J, Scrable $H$, et al. Fat tissue, aging, and cellular senescence. Aging Cell. 2010;9(5):667-84.

27. Tam CS, Lecoultre V, Ravussin E. Brown adipose tissue mechanisms and potential therapeutic targets. Circulation. 2012;125(22):2782-91.

28. Viengchareun S, Zennaro MC, Pascual-Le Tallec L, Lombes M. Brown adipocytes are novel sites of expression and regulation of adiponectin and resistin. FEBS Lett. 2002;532(3):345-50.
29. Drolet R, Belanger C, Fortier M, Huot C, Mailloux J, Legare D, et al. Fat depotspecific impact of visceral obesity on adipocyte adiponectin release in women. Obesity (Silver Spring). 2009;17(3):424-30.

30. Motoshima H, Wu X, Sinha MK, Hardy VE, Rosato EL, Barbot DJ, et al. Differential regulation of adiponectin secretion from cultured human omental and subcutaneous adipocytes: effects of insulin and rosiglitazone. J Clin Endocrinol Metab. 2002;87(12):5662-7.

31. Meyer LK, Ciaraldi TP, Henry RR, Wittgrove AC, Phillips SA. Adipose tissue depot and cell size dependency of adiponectin synthesis and secretion in human obesity. Adipocyte. 2013;2(4):217-26.

32. Hivert MF, Sun Q, Shrader P, Mantzoros CS, Meigs JB, Hu FB. Higher adiponectin levels predict greater weight gain in healthy women in the Nurses' Health Study. Obesity (Silver Spring). 2011;19(2):409-15.

33. Chalfant JS, Smith ML, Hu HH, Dorey FJ, Goodarzian F, Fu CH, et al. Inverse association between brown adipose tissue activation and white adipose tissue accumulation in successfully treated pediatric malignancy. Am J Clin Nutr. 2012;95(5):1144-9.

34. Dridi S, Taouis M. Adiponectin and energy homeostasis: consensus and controversy. J Nutr Biochem. 2009;20(11):831-9.

35. Chan TF, Yuan SS, Chen HS, Guu CF, Wu LC, Yeh YT, et al. Correlations between umbilical and maternal serum adiponectin levels and neonatal birthweights. Acta Obstet Gynecol Scand. 2004:83(2):165-9.

36. Ballesteros M, Simon I, Vendrell J, Ceperuelo-Mallafre V, Miralles RM, Albaiges $\mathrm{G}$, et al. Maternal and cord blood adiponectin multimeric forms in gestational diabetes mellitus: a prospective analysis. Diabetes Care. 2011; 34(11):2418-23.

37. Aye IL, Rosario FJ, Powell TL, Jansson T. Adiponectin supplementation in pregnant mice prevents the adverse effects of maternal obesity on placental function and fetal growth. Proc Natl Acad Sci U S A. 2015;112(41): 12858-63.

38. Rosario FJ, Schumacher MA, Jiang J, Kanai Y, Powell TL, Jansson T. Chronic maternal infusion of full-length adiponectin in pregnant mice downregulates placental amino acid transporter activity and expression and decreases fetal growth. J Physiol. 2012;590(Pt 6):1495-509.

\section{Submit your next manuscript to BioMed Central and we will help you at every step:}

- We accept pre-submission inquiries

- Our selector tool helps you to find the most relevant journal

- We provide round the clock customer support

- Convenient online submission

- Thorough peer review

- Inclusion in PubMed and all major indexing services

- Maximum visibility for your research

Submit your manuscript at www.biomedcentral.com/submit 